\title{
Cutaneous ganglioneuroma within a giant congenital nevus
}

\author{
Marcos RO Jaeger $M D^{1}$, Sandra Viero $M^{2}{ }^{2}$, Ronald M Zuker MD FRCSC FACS FAAP ${ }^{1}$
}

\begin{abstract}
MRO Jaeger, S Viero, RM Zuker. Cutaneous ganglioneuroma within a giant congenital nevus. Can J Plast Surg 2005;13(1):39-42.

Cutaneous ganglioneuroma has only occasionally been reported in the literature. Cutaneous ganglioneuroma is seen even more rarely in association with a giant congenital nevus. Differential diagnosis includes malignancies, especially melanoma and metastatic neuroblastoma.

It is essential to rule out malignancy in a solid lesion within a congenital nevus. The present report is possibly the first relating ganglioneuroma and a congenital nevus to a cervical mass detected during routine prenatal ultrasound.
\end{abstract}

Key Words: Congenital giant nevus; Cutaneous ganglioneuroma; Neck masses

Terve cell tumours are very rare. Ganglioneuromas are pri1 marily benign lesions developing in the sympathetic nervous system and most often arise in the posterior mediastinum, retroperitoneum and medullary portion of the adrenal gland (1). A small number of cases have been reported in the skin (1-10) and, most often, these lesions develop after birth. Ganglioneuromatous differentiation has rarely been reported within giant congenital melanocytic nevi or other skin lesions (11). Other nerve cell-related tumours should also be taken into consideration before making the diagnosis of ganglioneuroma. These include a well-differentiated cutaneous metastasis of neuroblastoma or ganglion cells entrapped by a plexiform neurofibroma in neurofibromatosis and especially the malignant neuroblastoma. We report the finding of ganglioneuromatous proliferation within a giant congenital melanocytic nevus that presented after birth at the exact location where a cystic mass was seen during routine prenatal ultrasound.

\section{CASE PRESENTATION}

A six-month-old male baby resulting from a twin pregnancy presented with a large pigmented lesion involving the nape of the neck, upper back, right shoulder and right upper chest, which was present at birth. At 16 weeks gestation, the male fetus was diagnosed as having a cystic hygroma during a routine ultrasound (Figure 1). At 30 weeks, the mother

\section{Un neurocytome cutané dans un naevus congénital géant}

Les neurocytomes cutanés sont peu déclarés dans la documentation scientifique. Ils sont encore plus rares en association avec un naevus congénital géant. Le diagnostic différentiel inclut la malignité, et surtout des mélanomes et des neuroblastomes métastatiques.

Il est impératif d'écarter la possibilité de malignité dans une lésion solide d'un naevus congénital. Le présent compte rendu est peut-être le premier reliant un neurocytome et un naevus congénital à une masse cervicale décelée pendant une échographie prénatale systématique.

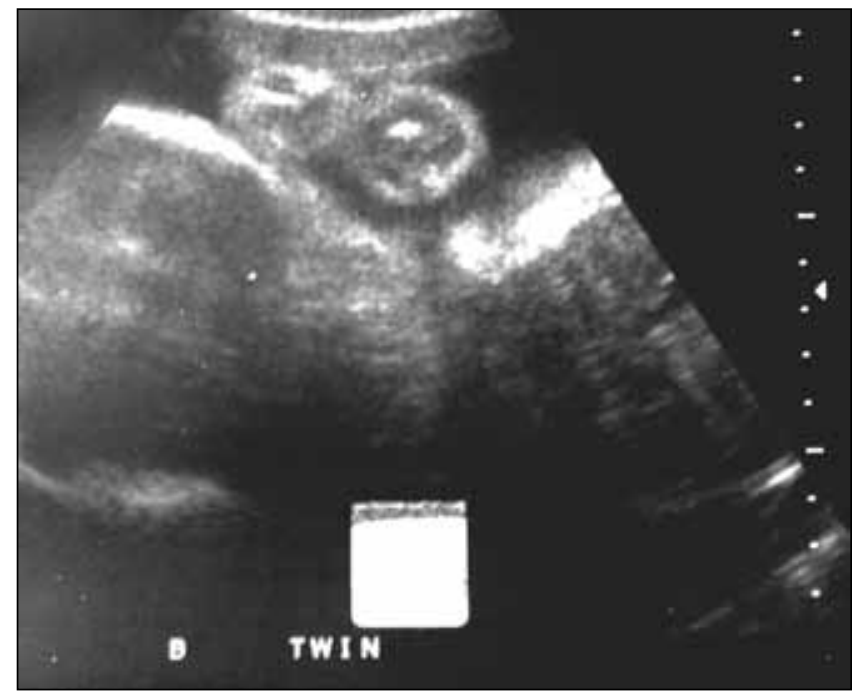

Figure 1) A cystic cervical mass was detected by routine ultrasound at 16 weeks gestation

underwent amniocentesis to rule out Down's syndrome. The cervical mass reduced in size as the pregnancy progressed and a cesarean section at 33 weeks gestation resulted in twins. On physical examination, a $2 \mathrm{~cm}$ round scarred area with alopecia

${ }^{1}$ Departments of Plastic Surgery and ${ }^{2}$ Pathology, The Hospital for Sick Children, Toronto, Ontario

Correspondence and reprints: Dr Ronald M Zuker, Suite 1524, 555 University Avenue, Toronto, Ontario M5G 1X8. Telephone 416-813-6447, fax 416-813-6147, e-mail ronald.zuker@sickkids.ca 

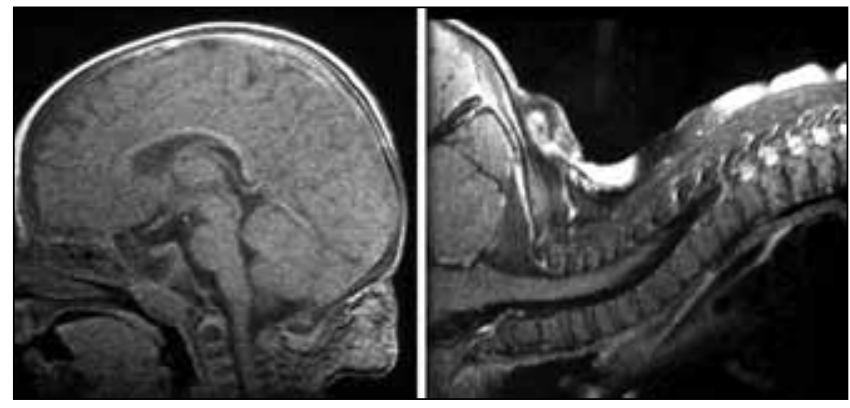

Figure 2) Cervical lesion presented after birth on magnetic resonance imaging

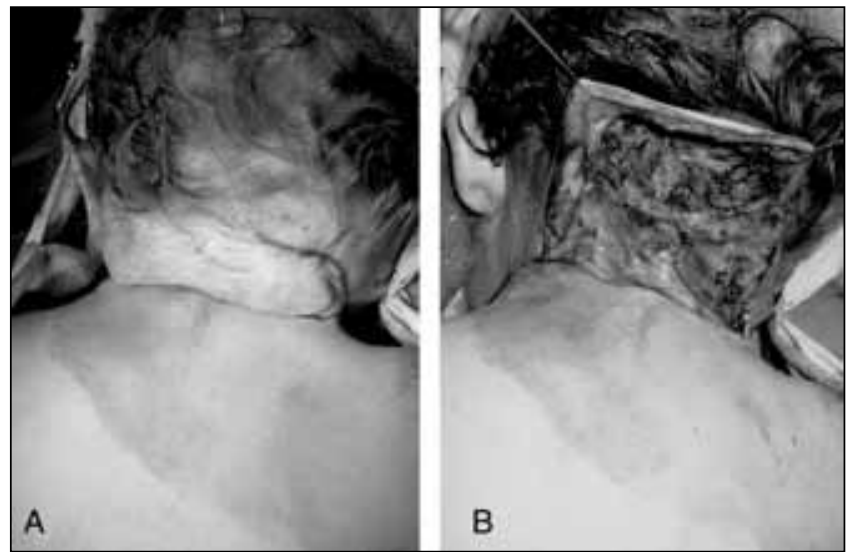

Figure 3) Intraoperative view: (A) Redundant fold of skin in pigmented area. (B) Flap elevated for excision of both pigmented skin and the solid tumour underneath

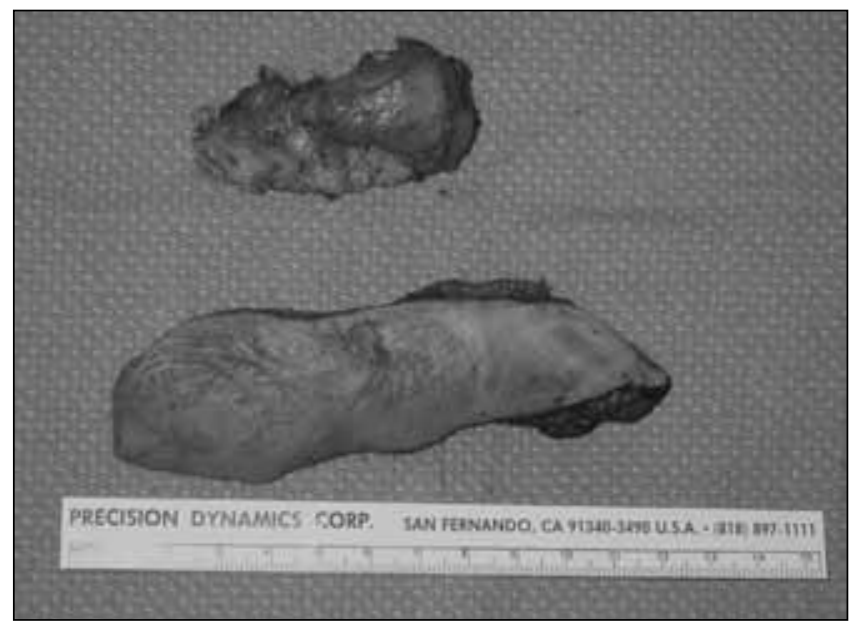

Figure 4) Two specimens. Above, the solid tumour

was perceptible on the occipital region, and a redundant fold of skin involving the posterior occipital scalp and nape of the neck was also observed. Beneath the nevus, a $1.5 \mathrm{~cm}$ rubbery mass was palpable. A magnetic resonance image taken shortly after birth showed early leptomeningeal melanocytic involvement, although liquor cytology was normal (Figure 2).

Surgical excision was undertaken at one year of age and consisted of the removal of a portion of the nevus and resection of the lump within the nevus (Figures $3 \mathrm{~A}$ and $3 \mathrm{~B}$ ). Two separate lesions were sent to pathology (Figure 4): the nevus and the deeper lesion found adherent to the periosteum. The excised melanocytic nevus measured $11.5 \mathrm{~cm} \times 3.5 \mathrm{~cm} \times 1.5 \mathrm{~cm}$,

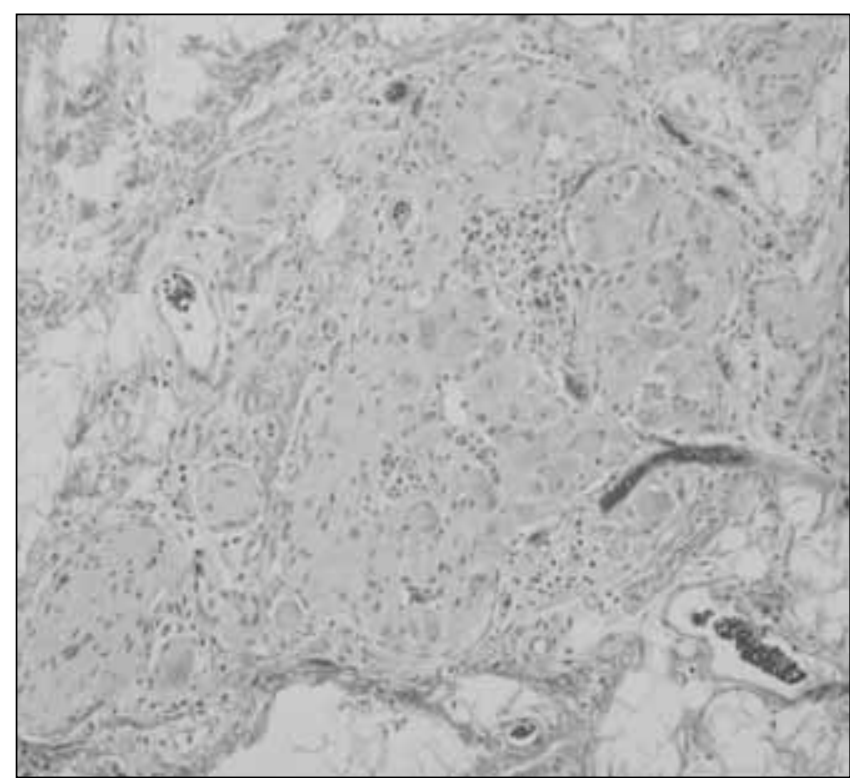

Figure 5) Detail of the histology of ganglioneuromatous proliferation showing typical cell arrangement

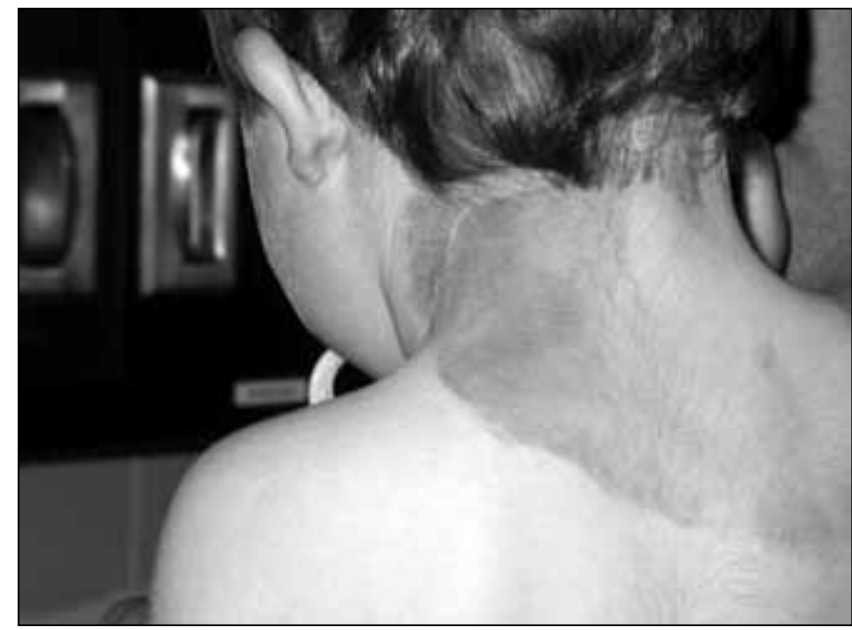

Figure 6) Result six months after solid lesion resection and partial removal of the giant nevus

while the deep tumour consisted of an oval shaped piece of fibrofatty tissue measuring $5 \mathrm{~cm} \times 2.5 \mathrm{~cm} \times 2 \mathrm{~cm}$. The findings were consistent with a giant melanocytic nevus, but the solid tumour underneath the nevus showed a haphazard ganglioneuromatous proliferation associated with chronic inflammation and increased fibroadipose tissue (Figure 5). The postoperative course was uneventful and at six months (Figure 6) there were no problems.

\section{DISCUSSION}

Neuroblastic tumours are the third most common neoplasm in early childhood, after leukemia and central nervous system tumours (12). They are the most common neoplasm in the first year of life, accounting for $7 \%$ to $20 \%$ of tumours and $15 \%$ of tumour-related deaths during the neonatal period $(13,14)$. Neuroblastic tumours are apudomas (ie, tumours composed of amine precursor uptake and decarboxylation cells) of neural or neural crest origin $(12,15)$ and are classified into three histological subgroups: neuroblastomas, ganglioneuromas and 
ganglioneuroblastomas. The three forms are not independent entities, but rather different developmental stages of the same disease. It is possible to find all three types in the same tumour $(15,16)$. Most often they represent intra-abdominal solid tumours, but in $2 \%$ to $5 \%$ of cases neuroblastic tumours can be observed in tumours of the cervical region. Neuroblastoma is often referred to as an intra-abdominal mass in infancy (1), and corresponds to the least differentiated form, with a high propensity for metastasis. On occasion, neuroblastoma arising within the abdomen may even metastasize to the neck. Spontaneous regression and maturation may also occur, as well as maturation to more benign forms and ganglioneuroma (17-20).

Ganglioneuromas arise in the sympathetic chains from the skull to the neck, posterior mediastinum, retroperitoneum and adrenal medulla $(7,8)$, and show a higher proportion of ganglioneuroma cells than neuroblasts. It is the most mature form of neuroblastic tumour and almost certainly has no metastatic potential (12). In general, the tumour is a distinctive, wellcircumscribed, round, firm nodule with a fibrous capsule, ranging from a few millimetres to several centimetres in size. It may be multiple and extensive, arising from neuroblastoma metastasis $(18,21)$, neurofibromatosis and endocrine adenomatosis $(8,22-24)$. Ganglioneuromas have also been known to expand within cutaneous lesions (1). The pathogenesis of cutaneous ganglioneuromas is still controversial, but it has been postulated that cutaneous ganglioneuroma is a combined heterotopia of ganglion cells and hamartomatous neuroma (4) or simply a choristoma in cases where the ganglion cells are present without the neurofibromatous component $(5,6)$. An important pathophysiological clue is the coexistence of the ganglion cells and the neuromatous component (8). Ganglion, satellite and Schwann cells are all neural crest derivatives and probably arrive together during embryogenesis. This strongly suggests an origin by aberrant migration and differentiation.

The pathology represents the essential tool in identifying the ganglioneuromatous component and is crucial in differentiating between other neural crest-related tumours. The ganglioneuromatous proliferation consists of a well-circumscribed white-gray, round, firm nodule with a fibrous capsule. Histologically, there is a relatively well-delimited spindle cell proliferation of axons and Schwann cells with interspersed mature ganglion cells. The spindle cells of the tumoural lesion

\section{REFERENCES}

1. Ohno S, Horiguchi Y, Shintaku M. A case of cutaneous ganglioneuroma developing within a lesion of seborrheic keratosis. J Dermatol 2002;29:300-4.

2. Collins JP, Johnson WC, Burgoon CF Jr. Ganglioneuroma of the skin. Arch Dermatol 1972;105:256-8.

3. Geffner RE, Hassell CM. Ganglioneuroma of the skin. Arch Dermatol 1986;122:377-8.

4. Lee JY, Martinez AJ, Abell E. Ganglioneuromatous tumor of the skin: A combined heterotopia of ganglion cells and hamartomatous neuroma: Report of a case. J Cutan Pathol 1988;15:58-61.

5. Rios JJ, Diaz-Cano SJ, Rivera-Hueto F, Villar JL. Cutaneous ganglion cell choristoma. J Cutan Pathol 1991;18:469-73.

6. Radice F, Gianotti R. Cutaneous ganglion cell tumor of the skin: Case report and review of the literature. Am J Dermatopathol 1993;15: 488-91.

7. Gambini C, Rongioletti F. Primary congenital cutaneous ganglioneuroma. J Am Acad Dermatol 1996;35:353-4.

8. Hammond RR, Walton JC. Cutaneous ganglioneuromas: A case report and review of the literature. Hum Pathol 1996;27:735-8.

9. Lloyd RV, James N, Breach NM, Fisher C. Development of ganglioneuroma following successful treatment for orbital rhabdomyosarcoma. Br J Plast Surg 1998;51:135-7. are positive for vimentin and S-100 protein, but negative for skeletal muscle-specific actin (HHF-35). The ganglion cells stain positively for glial fibrillary acidic protein and neurofilaments by routine immunohistochemistry. More importantly, the areas with ganglioneuromatous proliferation are identified by large cells with ganglionar differentiation with nuclei exhibiting prominent nucleoli in a notably fibrillary background. The presence of melanocytes containing different amounts of melanin and arranged in a collagenous interstitial matrix accounts for the melanocytic component in the present report.

The finding of a giant melanocytic nevus at the same site as a cutaneous ganglioneuromatous proliferation is not purely coincidental. Giant melanocytic nevi are also neural crestrelated (25). The neural crest is a derivative of the neuroepithelium and a precursor of over 50 different cell types, contributing to nerve cells of ganglia, Schwann cells and pigment cells, etc. Giant cutaneous melanocytic nevi may be seen with a large variety of constituent cells $(11,25,26)$. Several combinations of histological patterns can be seen, expressing many of the differentiating capabilities of the neural crest cells $(25,26)$. Sometimes, the giant congenital nevus may show microscopic features that are commonly seen in malignancy and melanoma $(27,28)$, including epithelioid melanocytes and the proliferative dermal collection of spindle cells; however, extreme caution must be taken to make the diagnosis in any such nevi during the first months of life $(25,26,29,30)$. Examples of other malignancies are rhabdomyosarcomas (29-31), poorly differentiated small cell tumours and undifferentiated sarcomas.

The relationship between nevus cells and ganglioneuromatous differentiation should be explicit. It was postulated that a kind of migration error may occur from time to time, even more frequently than observed clinically. Actual tumour formation, however, would be the result of the survival and maturation of these small nests by an unusual trophic environment. Ganglioneuroma was occasionally observed on the skin surface $(1-11)$, but only rarely in association with a giant congenital nevus (11). In all cases, with the exception of the primary ganglioneuroma described by Gambini and Rongioletti in Italy (7), they presented after birth. The current report is the first that we are aware of to describe ganglioneuromatous proliferation within a giant congenital nevus arising in the same location of an intrauterine cystic mass.

10. Franchi A, Massi D, Santucci M. Desmoplastic cutaneous ganglioneuroma. Histopathology 1999;34:82-4.

11. Drut R, Drut RM, Cohen M. Adnexal-centered giant congenital melanocyte nevus with extensive ganglioneuromatous component and trisomy 7. Pediatr Dev Pathol 1999;2:473-7.

12. Moukheiber AK, Nicollas R, Roman S, Coze C, Triglia JM. Primary pediatric neuroblastic tumors of the neck. Int J Pediatr Otorhinolaryngol 2001;60:155-61.

13. Cunningham MJ, Myers EN, Bluestone CD. Malignant tumors of the head and neck in children: A twenty-year review. Int J Pediatr Otorhinolaryngol 1987;13:279-92.

14. Lopez-Ibor B, Schwartz AD. Neuroblastoma. Pediatr Clin North Am 1985;32:755-78.

15. Bergman KS, Harris BH. Scalp and neck masses. Pediatr Clin North Am 1993;40:1151-60.

16. Shimada H, Ambros IM, Dehner LP, Hata J, Joshi VV, Roald B. Terminology and morphologic criteria of neuroblastic tumors: Recommendations by the International Neuroblastoma Pathology Committee. Cancer 1999;86:349-63.

17. Iwanaka T, Yamamoto K, Ogawa Y, et al. Maturation of massscreened localized adrenal neuroblastoma. J Pediatr Surg 2001;36:1633-6. 
18. Griffin ME, Bolande RP. Familial neuroblastoma with regression and maturation to ganglioneurofibroma. Pediatrics 1969;43:377-82.

19. Dawson DA. Nerve cell tumours of the neck and their secretory activity. J Laryngol Otol 1970;84:203-16.

20. Jaffe N. Neuroblastoma: Review of the literature and an examination of factors contributing to its enigmatic character. Cancer Treat Rev 1976;3:61-82.

21. Bolande RP, Towler WF. A possible relationship of neuroblastoma to von Recklinghausen's disease. Cancer 1970;26:162-75.

22. Al-Jassim AH. Cervical ganglioneuroblastoma. J Laryngol Otol 1987;101:296-301.

23. Smith MC, Smith RJ, Bailey CM. Primary cervical neuroblastoma in infants. J Laryngol Otol 1985;99:209-14.

24. Evans AE, D'Angio GJ, Koop CE. Diagnosis and treatment of neuroblastoma. Pediatr Clin North Am 1976;23:161-70.

25. Isaacs H Jr. Tumors of the Fetus and Newborn. Philadelphia: WB Saunders, 1997:114-9.

26. Elder DE, Murphy GF. Melanocytic tumors of the skin. In: Atlas of
Tumor Pathology. Washington, DC: Armed Forces Institute of Pathology, 1991;64-78.

27. Hendrickson MR, Ross JC. Neoplasms arising in congenital giant nevi: Morphologic study of seven cases and a review of the literature. Am J Surg Pathol 1981;5:109-35.

28. Mancianti ML, Clark WH, Hayes FA, Herlyn M. Malignant melanoma simulants arising in congenital melanocytic nevi do not show experimental evidence for a malignant phenotype. Am J Pathol 1990;136:817-29.

29. Angelucci D, Natali PG, Amerio PL, Ramenghi M, Musiani P. Rapid perinatal growth mimicking malignant transformation in a giant congenital melanocytic nevus. Hum Pathol 1991;22:297-301.

30. Zuniga S, Las Heras J, Benveniste S. Rhabdomyosarcoma arising in a congenital giant nevus associated with neurocutaneous melanosis in a neonate. J Pediatr Surg 1987;22:1036-8.

31. Schmitt FC, Bittencourt A, Mendonca N, Dorea M. Rhabdomyosarcoma in a congenital pigmented nevus. Pediatr Pathol 1992;12:93-8. 